\title{
Stigma towards Eating Disorders among Attendees and Non-Attendees of Outreach Events
}

\author{
Zornitsa Kalibatseva ${ }^{1}$, Molly S. Arnold ${ }^{1}$, Kathleen E. Connelly ${ }^{1}$, Marissa L. Marottoli ${ }^{1}$, Julia Tominberg ${ }^{1}$, \\ Christine Ferri ${ }^{1} \&$ Nathan Morell ${ }^{2}$ \\ ${ }^{1}$ Social and Behavioral Sciences, Stockton University, 101 Vera King Farris Drive, Galloway, NJ 08205, United \\ States of America \\ ${ }^{2}$ Counseling Center, Stockton University, 101 Vera King Farris Drive, Galloway, NJ 08205, United States of \\ America \\ Correspondence: Zornitsa Kalibatseva, Social and Behavioral Sciences, Stockton University, 101 Vera King \\ Farris Drive, Galloway, NJ 08205, United States of America.
}

Received: March 11, 2021

Accepted: April 12, 2021

Online Published: April 17, 2021

doi:10.5539/ijps.v13n2p14

URL: https://doi.org/10.5539/ijps.v13n2p14

\begin{abstract}
Eating disorders are among the most stigmatized psychological disorders. Individuals with eating disorders are often blamed for their disorder. Stigma acts as a significant barrier to treatment. Health promotion outreach programs can successfully change knowledge, attitudes, and behaviors associated with disordered eating. The current study examined eating disorder stigma scores among attendees of Disordered Eating Awareness and Prevention week events at a public US university and compared their stigma scores to college students who did not attend the events. The study recruited 332 participants $(n=159$ attendees, $n=173$ non-attendees). Attendees completed a paper-and-pencil survey after each event and non-attendees participated in an online survey. The study found that participants who attended disordered eating outreach events reported lower stigma scores than those who did not attend. Furthermore, female gender and having a family member with an eating disorder was associated with lower stigma scores; however, having an eating disorder was not. The findings emphasize the importance of integrating stigma assessment in outreach programs and reducing stigma associated with eating disorders.
\end{abstract}

Keywords: disordered eating, eating disorders, health promotion, outreach, stigma

\section{Introduction}

Stigma towards individuals diagnosed with psychological disorders is widespread and there is ample research on the topic of conceptualizing and measuring it (Fox, Earnshaw, Taverna, \& Vogt, 2018). Stigma beliefs and actions may vary for different psychological disorders; moreover, some disorders may be more stigmatized than others (Stewart, Schiavo, Herzog, \& Franko, 2008). In particular, previous research found that eating disorders were more stigmatized than depression (Roehrig \& McLean, 2010). Moreover, people with eating disorders reported frequently experiencing stigma and being blamed or judged for their eating disorder ( $\mathrm{O}^{\prime}$ Connor, McNamara, O'Hara, McNicholas, \& McNicholas, 2019).

The high levels of stigma associated with eating disorders may be related to the misperception that individuals with eating disorders have control over their condition and choose to inflict it upon themselves. As a result, people may blame them for having an eating disorder (O'Connor et al., 2019; Stewart, Keel, \& Schiavo, 2006). Individuals with eating disorders are also often perceived as fragile and seeking attention, as well as responsible for their disorder (Dimitropolous, Freeman, Muskat, Domingo, \& McCallum, 2016; Roehrig \& McLean, 2010). In addition, individuals with eating disorders may experience self-stigma as they internalize public stigma about eating disorders ( $\mathrm{O}^{\prime}$ Connor et al., 2019). Mental health promotion outreach events attempt to raise awareness and combat stigma associated with psychological disorders. This study sought to examine how stigma toward eating disorders may vary among people who attended disordered eating outreach events and those who did not.

Self-stigmatizing attitudes and behaviors may also play a role in an individual's likelihood to seek out the help they need. As individuals continue to experience public stigma, they start to experience more marked eating disorder symptoms, a longer duration of illness, lower self-esteem, and greater self-stigma towards seeking psychological 
help (Griffiths, Mond, Murray, \& Touyz, 2014). Stigma internalization was related to alienation and social withdrawal, which, in turn, predicted higher severity of eating disorder symptoms (Griffiths, Mitchison, Murray, Mond, \& Bastian, 2018). Aside from internal stigma, individuals may also experience stigma in their families (O'Connor et al., 2019). In some cases, people who have a psychological disorder report stigmatizing treatment from family members in the form of distrust, exclusion from family events, teasing, and low expectations (Moses, 2010).

At the same time, not all stereotypes about individuals with eating disorders are negative. In particular, eating disorders may be associated with higher sociability and outgoingness than other disorders (Katterman \& Klump, 2010). People with eating disorders may even be seen as admirable in the ability to "control their eating habits" (Roehrig \& McLean, 2010). Disordered eating behaviors may also be positively reinforced with praises of losing weight and restricting one's eating. Although these stereotypes may not appear negative, these views are problematic, as they undermine the severity of eating disorders and may delay seeking help.

Eating disorders have a typical onset between the ages 16-20, which places traditional college students at high risk (Stice, Marti, \& Rohde, 2013). Furthermore, the prevalence of eating disorders among college females may be increasing as one study showed prevalence rates increasing from 23\% to 32\% between 1995 and 2008 (White, Reynolds-Malear, \& Cordero, 2011). Moreover, disordered eating is prevalent in adolescents and college students and serves as a risk factor for eating disorders (Stice et al., 2013).

College campuses employ a variety of disordered eating outreach programs and health promotion outreach programs including educational events and workshops, athletic department services, counseling services, and residential life programs (National Eating Disorders Association, 2013). Students who attended one outreach program about eating disorder awareness showed higher knowledge about disordered eating behaviors than student non-attendees (Tillman, Arbaugh, \& Balaban, 2012). Increasing health promotion efforts can lower the health burden of disordered eating, including stigma towards the individuals who are suffering from disordered eating and encouraging early intervention for those individuals (Mond, 2015). Besides knowledge increase, health promotion outreach programs may reduce stigma and encourage help-seeking behavior (National Eating Disorders Association, 2013).

To date, no study has measured eating disorders stigma among attendees and non-attendees of outreach events. The current study compared eating disorder (ED) stigma among attendees and non-attendees of Disordered Eating Awareness and Prevention week events at a public Northeastern US university. Based on previous research, we hypothesized that students who attend outreach events would have lower ED stigma scores after the event than students who did not attend outreach events. In addition, the study explored the association of other factors with ED stigma (i.e., gender, having a diagnosis of ED, having a family member with ED, taking an abnormal psychology class, and age).

\section{Method}

\subsection{Participants}

A total of 332 participants completed the study in 2016. The majority of the sample identified as White $(n=245$, $75.2 \%)$, followed by Hispanic $(n=32,9.8 \%)$, Black $(n=22,6.7 \%)$, Other $(n=12,3.7 \%)$, Asian $(n=10,3.1 \%)$, Multiracial $(n=3,0.9 \%)$, Native American $(n=1,0.3 \%)$, and Hawaiian $(n=1,0.3 \%)$. Data about race/ethnicity was missing for $6(1.8 \%)$ participants. Approximately half of the sample $(n=159,47.9 \%)$ attended outreach events on disordered eating and completed a paper-and-pencil questionnaire. The other half $(n=173,52.1 \%)$ did not attend any outreach events and completed the questionnaire online. The majority of participants identified as female $(n=265,79.8 \%)$, followed by male $(n=65,19.6 \%)$, and two participants $(0.6 \%)$ were missing gender data. The mean age of all participants was 20.67 years old $(S D=3.93)$. A chi-square test indicated a significant difference in gender between attendees and non-attendees, with significantly more females than males in the attendee group, $\chi^{2}=23.01, p<.001$. Table 1 shows demographic information for all participants by group. 
Table 1. Demographics by Group

\begin{tabular}{|c|c|c|c|c|c|}
\hline & & Attend & & Non- & \\
\hline & & $M / n$ & $S D / \%$ & $M / n$ & $S D / \%$ \\
\hline Age & & 20.96 & 3.73 & 20.41 & 4.10 \\
\hline Gender & & 159 & 100 & 171 & 98.8 \\
\hline & Female & 145 & 91.2 & 120 & 70.2 \\
\hline & Male & 14 & 8.8 & 51 & 29.8 \\
\hline Race & & 156 & 98.1 & 170 & 98.3 \\
\hline & $\begin{array}{l}\text { Native } \\
\text { American }\end{array}$ & 0 & 0 & 1 & .6 \\
\hline & Asian & 3 & 1.9 & 7 & 4.1 \\
\hline & Black & 6 & 3.8 & 16 & 9.4 \\
\hline & Hawaiian & 0 & 0 & 2 & .6 \\
\hline & Hispanic & 11 & 7.1 & 21 & 12.4 \\
\hline & Multiracial & 3 & 1.9 & 0 & 0 \\
\hline & Other & 5 & 3.2 & 7 & 4.1 \\
\hline & White & 128 & 82.1 & 117 & 68.8 \\
\hline Eating disorder (self) & & 159 & 100 & 173 & 100 \\
\hline & Yes & 5 & 3.1 & 9 & 5.2 \\
\hline & No & 154 & 3.1 & 164 & 94.8 \\
\hline Eating disorder (family) & & 159 & 100 & 172 & 99.4 \\
\hline & Yes & 80 & 50.3 & 77 & 44.8 \\
\hline & No & 79 & 49.7 & 95 & 55.2 \\
\hline
\end{tabular}

\subsection{Procedure}

Attendees of the Disordered Eating Awareness and Prevention Week at a public Northeastern university completed questionnaires at the end of four different outreach events: a documentary screening with discussion, student stories, a national speaker, and a binge-eating workshop. Participation was voluntary and anonymous. Non-attendee control group data was collected via the university's Psychology Research Participant Pool. The university's Institutional Review Board approved the study. The data that support the findings of this study are available from the corresponding author upon reasonable request.

\subsection{Measures}

Demographics. Participants reported their age, gender, race/ethnicity, diagnosis of ED for oneself and for family members, and enrollment in an abnormal psychology class (among non-attendees only).

Eating Disorder Stigma Scale (EDDS). This 20-item measure examines stigma toward eating disorders (Crisafulli et al., 2010). Each item is rated on a 5-point Likert scale (1 = strongly disagree to $5=$ strongly agree). There are four subscales: Blame ("they are responsible for their eating disorder"), Weak ("their eating disorder represents a weakness in their character"), Selfish/vain ("they only care about looking good"), and Trivial ("their illness is not as serious as other mental illnesses"). A total score is created by adding up all item ratings. Cronbach $\alpha$ s for the EDDS subscales and total score in this study were: Blame (.64), Weak (.88), Selfish/vain (.89), Trivial (.91), and Stigma Total (.89). These results are consistent with Cronbach $\alpha$ s reported in the original EDDS study: Blame (.80), Weak (.83), Selfish/vain (.83), Trivial (.86), and Stigma Total (.90; Cristafulli et al., 2010).

\section{Results}

Independent $t$-tests revealed that attendees' ED total stigma scores were significantly lower than non-attendees' scores. Moreover, attendees scored lower on all subscales than non-attendees (see Table 2). 
Table 2. Comparison of Eating Disorder Stigma Subscale Scores among Attendees and Non-Attendees

\begin{tabular}{llllllll}
\hline & \multicolumn{9}{l}{ Attendees } & \multicolumn{2}{l}{ Non-Attendees } \\
\hline \multirow{3}{*}{ Blame } & $M$ & $S D$ & $M$ & $S D$ & $t$ & $d f$ & Cohen's $d$ \\
Trivial & 7.82 & 3.29 & 10.20 & 2.96 & $-6.93^{*}$ & 326 & 0.76 \\
Weakness & 5.57 & 1.91 & 8.40 & 3.21 & $-9.93^{*}$ & 330 & 1.11 \\
Selfish & 5.58 & 1.84 & 8.49 & 3.25 & $-11.42^{*}$ & 327 & 1.28 \\
Total & 6.73 & 1.73 & 10.68 & 4.01 & $-9.67^{*}$ & 330 & 1.07 \\
\hline
\end{tabular}

$* p<.01$

An analysis of covariance (ANCOVA) with total stigma score as the dependent variable, event attendance as the independent variable, and gender, diagnosis of ED, and family history of ED as covariates was conducted. The results revealed that students who attended an outreach event $(M=25.72, S D=7.02)$ reported significantly less stigma towards eating disorders than those who did not attend an event $(M=37.91, S D=11.07), F(1,318)=$ $108.79, p<.001$, partial $\eta^{2}=.26$. Identifying as female $(M=29.85, S D=9.97)$ was associated with a lower stigma score, $t(322)=-7.75, p<.001$. Additionally, having a family member with an eating disorder diagnosis was associated with less stigma $(M=29.67, S D=10.02), t(323)=3.63, p<.001$. However, having an eating disorder diagnosis was not a statistically significant covariate. Additionally, students who took an abnormal psychology class $(M=35.17, S D=8.92)$ among the non-attendees also reported lower stigma scores than those who did not take an abnormal psychology class $(M=39.04, S D=11.78), t(167)=2.15, p<.05$. Total scores of stigma and subscale scores for stigma blame were also positively correlated with age $(r=.12, p<.05$ and $r=.16, p<.01$, respectively).

\section{Discussion}

Stigma against individuals with psychological disorders is widespread and eating disorders are more stigmatized than other psychological disorders, such as depression (Roehrig \& McLean, 2010). Misinformation continuously perpetuates the stigma against people with an eating disorder as they are blamed for their disorder and perceived as vain and selfish attention-seekers (Roehrig \& McLean, 2010). This misinformation can also lead to increase in self-stigma, which often prevents individuals from seeking the help they need (Griffiths, Mond, Murray, \& Touyz, 2014). Though percentages may vary, approximately $20 \%$ of college-aged women have an eating disorder (Tillman et al., 2012). Therefore, it is important to take actions to reduce stigma towards eating disorders and provide services for at-risk groups.

Previous research demonstrated that students who had attended eating disorder awareness programs showed more knowledge about disordered eating behaviors (Tillman et al., 2012). It is important to increase public knowledge in hopes to reduce the stigma surrounding disordered eating and increase early intervention (Mond, 2014). However, prior to this study, it was unclear whether attendees of these outreach programs had a lower stigma score as compared to non-attendees.

This study found that individuals who attended outreach health promotion events reported significantly less stigma toward people with eating disorders than non-attendees for all subscales of the EDDS. In addition, the subscales help to examine stigma related to blame, weakness, selfishness/vanity, and triviality. Although there was a strong relationship (Cohen's $d=1.31$ ) between attending the outreach events and having lower ED stigma scores, the study could not establish a cause-and-effect relationship. Individuals that chose to participate in these outreach events may differ systematically from those who did not, as participants were more likely to be female, may have had a personal interest in eating disorders, and participation was encouraged among students enrolled in social science classes. Hence, the next analysis controlled for factors that may be associated with lower stigma scores and still found a significant difference with attendees reporting lower stigma scores than non-attendees.

Besides the outreach events, factors associated with lower stigma scores include identifying as female, having a family member with an ED, and completing an abnormal psychology course. This finding suggests that males may experience more stigma and possibly less empathy towards people with eating disorders than females (Mitchison \& Mond, 2015). In particular, males may be more likely to minimize the symptoms of eating disorders, and to view them as less distressing than females (Mitchison \& Mond, 2015). They may be also more likely to view people with disordered eating as not deserving of sympathy or not requiring intensive treatment (Mond \& Arrighi, 2011). In addition, men are also less likely to participate in outreach programs than women (Simpson \& Mazzeo, 2017). These findings are consistent with our finding that males experience more stigma towards people with eating disorders than females.

The familial factor suggests that being exposed to a family member with an eating disorder could help people to 
understand better the individual's experience. Families may experience isolation, diminished reputations, and damage to relationships because of the actions of a family member with a psychological disorder (Lefley, 1989). Since family members sometimes experience the same level of stigmatization, they may relate to the feelings of isolation that individuals with a psychological disorder experience. Findings suggest that individuals with a family member who was diagnosed with an eating disorder are more likely to believe that it is important for those suffering from an eating disorder to receive attention from others as compared to those without a family member diagnosed with an eating disorder. This is specifically seen in individuals whose family member was diagnosed with anorexia nervosa (Mond, 2006). Additionally, non-attendees who took an abnormal psychology class had lower stigma scores than non-attendees who did not, suggesting that knowledge about eating disorders and other psychological disorders may be associated with less stigma. Consistent with this finding, attendees of a one-time intervention program showed higher levels of factual knowledge of campus resources and eating disorder awareness than non-attendees (Tillman et al., 2012). Interestingly, older individuals reported higher overall levels of stigma and were more likely to blame people with eating disorders for their condition. However, the findings about the relationship between age and stigma are very mixed as a meta-synthesis found that public stigma was greater among younger adults (Clement et al., 2015) and others found older individuals reported lower levels of mental health stigma for generalized anxiety disorder and schizophrenia (Bradbury, 2020).

Self-reported diagnosis of an eating disorder was not associated with less ED stigma. This may be due to the internalization of stigma, such as self-blame or guilt. When individuals feel they should be able to "pull themselves together" or that "they are personally responsible for their condition," they may be less likely to seek the professional help they need, leading to more feelings of insecurity and depression (Griffiths et al., 2014). Research shows that the perception of stigmatizing beliefs of others towards an individual can lead to poorer health and continuation of disordered eating habits in the individual (Palmeira et al., 2017). Higher levels of internalized stigma towards disordered eating are positively correlated with negative self-evaluations of physical appearance among overweight and obese individuals (Palmeira et al., 2017).

Limitations of this study included not being able to establish a cause-and-effect relationship and having predominantly female attendees at the events. Future studies may consider administering pre- and post- tests of attendees and recruiting a more diverse population in terms of race/ethnicity and gender. In addition, it may help to focus on stigma changes over time and assess the impact of repeated exposure to outreach health promotion programs. It may also be beneficial to explore how people with eating disorders internalize stigma as the study did not find one's diagnosis of an eating disorder to be associated with lower stigma scores. Implications for future health promotion and treatment programs include assessing and actively addressing stigma of eating disorders among individuals with such disorders as well as reaching out to populations that may be more likely to hold stigmatized views of eating disorders, such as males.

\section{References}

Bradbury, A. (2020). Mental health stigma: The impact of age and gender on attitudes. Community Mental Health Journal, 56, 933-938. https://doi.org/10.1007/s10597-020-00559-x

Clement, S., Schauman, O., Graham, T., Maggioni, F., Evans-Lacko, S., Bezborodovs, N.,... Thornicroft, G. (2015). What is the impact of mental health-related stigma on help-seeking? A systematic review of quantitative and qualitative studies. Psychological Medicine, 45(1), 11-27. https://doi.org/10.1017/S0033291714000129

Crisafulli, M. A., Thompson-Brenner, H., Franko, D. L., Eddy, K. T., \& Herzog, D. B. (2010). Stigmatization of anorexia nervosa: Characteristics and response to intervention. Journal of Social and Clinical Psychology, 29(7), 756-770. https://doi.org/10.1521/jscp.2010.29.7.756

Dimitropoulos, G., Freeman, V. E., Muskat, S., Domingo, A., \& McCallum, L. (2016). You don't have anorexia, you just want to look like a celebrity: Perceived stigma in individuals with anorexia nervosa. Journal of Mental Health, 25(1), 47-54. https://doi.org/10.3109/09638237.2015.1101422

Fox, A. B., Earnshaw, V. A., Taverna, E. C., \& Vogt, D. (2018). Conceptualizing and measuring mental illness stigma: The Mental Illness Stigma Framework and critical review of measures. Stigma and Health, 3, 348-376. https://doi.org/10.1037/sah0000104

Griffiths, S., Mithcison, D., Murray, S. B., Mond, J. M., \& Bastian, B. B. (2018). How might eating disorders stigmatization worsen eating disorder symptom severity? Evaluation of stigma internalization model. International Journal of Eating Disorders, 51(8), 1010-1014. https://doi.org/10.1002/eat.22932

Griffiths, S., Mond, J. M., Murray, S. B., \& Touyz, S. (2014). The prevalence and adverse associations of stigmatization in people with eating disorders. International Journal of Eating Disorders, 48(6), 767-774. https://doi.org/10.1002/eat.22353 
Katterman, S. N., \& Klump, K. L. (2010). Stigmatization of eating disorders: a controlled study of the effects of the television show Starved. Eating Disorders, 18, 153-164. https://doi.org/10.1080/10640260903585599

Lefley, H. P. (1989). Family burden and family stigma in major mental illness. American Psychologist, 44(3), 556-560. https://doi.org/10.1037/0003-066X.44.3.556

Mitchison, D., \& Mond, J. (2015). Epidemiology of eating disorders, eating disordered behaviour, and body image disturbance in males: A narrative review. Journal of Eating Disorders, 3(1). https://doi.org/10.1186/s40337-015-0058-y

Mond, J. M. (2014). Eating disorders "mental health literacy": An introduction. Journal of Mental Health, 23(2), 51-54. https://doi.org/10.3109/09638237.2014.889286

Mond, J. M. (2015). Optimizing prevention programs and maximizing public health impact are not the same thing. Eating Disorders, 24(1), 20-28. https://doi.org/10.1080/10640266.2015.1113824

Mond, J. M., \& Arrighi, A. (2011). Gender differences in perceptions of the severity and prevalence of eating disorders. Early Intervention in Psychiatry, 5(1), 41-49. https://doi.org/10.1111/j.1751-7893.2010.00257.x

Mond, J. M., Robertson-Smith, G., \& Vetere, A. (2006). Stigma and eating disorders: Is there evidence of negative attitudes towards anorexia nervosa among women in the community? Journal of Mental Health, 15(5), 519-532. https://doi.org/10.1080/09638230600902559

Moses, T. (2010). Being treated differently: Stigma experiences with family, peers, and school staff among adolescents with mental disorders. Social Science \& Medicine, 70(7), 985-993. https://doi.org/10.1016/j.socscimed.2009.12.022

National Eating Disorder Association. (2013). Eating disorders on the college campus: A national survey of programs and resources. Retrieved from https://www.nationaleatingdisorders.org/sites/default/files/CollegeSurvey/CollegiateSurveyProject.pdf

O’Connor, C., McNamara, N., O’Hara, L., McNicholas, M., \& McNicholas, F. (2019). How do people with eating disorders experience the stigma associated with their condition? A mixed-methods systematic review. Journal of Mental Health. https://doi.org/10.1080/09638237.2019.1685081

Palmeira, L., Pinto-Gouveia, J., Cunha, M., \& Carvalho, S. (2017). Finding the link between internalized weight-stigma and binge eating behaviors in Portuguese adult women with overweight and obesity: The mediator role of self-criticism and self-reassurance. Eating Behaviors, 26, 50-54. https://doi.org/10.1016/j.eatbeh.2017.01.006

Roehrig, J. P., \& McLean, C. P. (2010). A comparison of stigma toward eating disorders versus depression. International Journal of Eating Disorders, 43(3), 671-674. https://doi.org/10.1002/eat.20760

Simpson, C. C., \& Mazzeo, S. E. (2017). Attitudes toward orthorexia nervosa relative to DSM-5 eating disorders. International Journal of Eating Disorders, 50(7), 781-792. https://doi.org/10.1002/eat.22710

Stewart, M., Keel, P. K., \& Schiavo, R. S. (2006). Stigmatization of anorexia nervosa. International Journal of Eating Disorders, 39(4), 320-325. https://doi.org/10.1007/s40519-019-00655-2

Stewart, M., Schiavo, R. S., Herzog, D. B., \& Franko, D. L. (2008). Stereotypes, prejudice and discrimination of women with anorexia nervosa. European Eating Disorders Review, 16, 311-318. https://doi.org/10.1002/erv.849

Stice, E., Marti, C. N., \& Rohde, P. (2013). Prevalence, incidence, impairment, and course of the proposed DSM-5 eating disorder diagnoses in an 8-year prospective community study of young women. Journal of Abnormal Psychology, 122(2), 445-457. https://doi.org/10.1037/a0030679

Tillman, K. S., Arbaugh, T. Jr., \& Balaban, M. S. (2012). Campus programming for National Eating Disorders. Awareness Week: An investigation of stigma, help-seeking, and resource knowledge. Eating Behaviors, 13(3), 281-284. https://doi.org/10.1016/j.eatbeh.2012.03.010

White, S., Reynolds-Malear, J. B., \& Cordero, E. (2011). Disordered eating and the use of unhealthy weight control methods in college students: 1995, 2002, and 2008. Eating Disorders: The Journal of Treatment \& Prevention, 19, 323-334. https://doi.org/10.1080/10640266.2011.584805

\section{Copyrights}

Copyright for this article is retained by the author(s), with first publication rights granted to the journal.

This is an open-access article distributed under the terms and conditions of the Creative Commons Attribution license (http://creativecommons.org/licenses/by/4.0/). 